\title{
Physiological responses and transcriptomic changes reveal the mechanisms underlying adaptation of Stylosanthes guianensis to phosphorus deficiency
}

Zhijian Chen', Jianling Song ${ }^{1,2}$, Xinyong Li', Jacobo Arango ${ }^{3}$, Juan Andres Cardoso ${ }^{3}$, Idupulapati Rao ${ }^{3}$, Rainer Schultze-Kraft ${ }^{3}$, Michael Peters ${ }^{3}$, Xiaohui $\mathrm{Mo}^{4^{*}}$ and Guodao Liu ${ }^{1^{*}}$

\begin{abstract}
Background: Phosphorus (P) is an essential macronutrient for plant growth that participates in a series of biological processes. Thus, P deficiency limits crop growth and yield. Although Stylosanthes guianensis (stylo) is an important tropical legume that displays adaptation to low phosphate (Pi) availability, its adaptive mechanisms remain largely unknown.

Results: In this study, differences in low-P stress tolerance were investigated using two stylo cultivars ('RY2' and 'RY5') that were grown in hydroponics. Results showed that cultivar RY2 was better adapted to Pi starvation than RY5, as reflected by lower values of relative decrease rates of growth parameters than RY5 at low-P stress, especially for the reduction of shoot and root dry weight. Furthermore, RY2 exhibited higher P acquisition efficiency than RY5 under the same P treatment, although P utilization efficiency was similar between the two cultivars. In addition, better root growth performance and higher leaf and root APase activities were observed with RY2 compared to RY5. Subsequent RNA-seq analysis revealed 8,348 genes that were differentially expressed under $P$ deficient and sufficient conditions in RY2 roots, with many Pi starvation regulated genes associated with P metabolic process, protein modification process, transport and other metabolic processes. A group of differentially expressed genes (DEGs) involved in Pi uptake and Pi homeostasis were identified, such as genes encoding Pi transporter (PT), purple acid phosphatase (PAP), and multidrug and toxin extrusion (MATE). Furthermore, a variety of genes related to transcription factors and regulators involved in Pi signaling, including genes belonging to the PHOSPHATE STARVATION RESPONSE 1-like (PHR1), WRKY and the SYG1/PHO81/XPR1 (SPX) domain, were also regulated by P deficiency in stylo roots.
\end{abstract}

Conclusions: This study reveals the possible mechanisms underlying the adaptation of stylo to P deficiency. The low-P tolerance in stylo is probably manifested through regulation of root growth, Pi acquisition and cellular $\mathrm{Pi}$

\footnotetext{
*Correspondence: xhmo@scau.edu.cn; liuguodao2008@163.com ${ }^{1}$ Institute of Tropical Crop Genetic Resources, Chinese Academy of Tropical Agricultural Sciences, Haikou 571101, P.R. China

${ }^{4}$ Root Biology Center, State Key Laboratory for Conservation and Utilization of Subtropical Agro-bioresources, College of Natural Resources and Environment, South China Agricultural University, Guangzhou 510642, P.R. China

Full list of author information is available at the end of the article
}

(C) The Author(s) 2021. Open Access This article is licensed under a Creative Commons Attribution 4.0 International License, which permits use, sharing, adaptation, distribution and reproduction in any medium or format, as long as you give appropriate credit to the original author(s) and the source, provide a link to the Creative Commons licence, and indicate if changes were made. The images or other third party material in this article are included in the article's Creative Commons licence, unless indicated otherwise in a credit line to the material. If material is not included in the article's Creative Commons licence and your intended use is not permitted by statutory regulation or exceeds the permitted use, you will need to obtain permission directly from the copyright holder. To view a copy of this licence, visit http://creativecommons.org/licenses/by/4.0/. The Creative Commons Public Domain Dedication waiver (http://creativeco mmons.org/publicdomain/zero/1.0/) applies to the data made available in this article, unless otherwise stated in a credit line to the data. 
homeostasis as well as Pi signaling pathway. The identified genes involved in low-P tolerance can be potentially used to design the breeding strategy for developing P-efficient stylo cultivars to grow on acid soils in the tropics.

Keywords: Stylosanthes, P deficiency, Transcriptomics, P responsive genes, Root morphology, Pi homeostasis

\section{Background}

Phosphorus $(\mathrm{P})$ is one of the essential macronutrients for plant growth and development. $\mathrm{P}$ is involved in the processes of photosynthesis, respiration, energy metabolism and signal transduction in plants [1]. Furthermore, $\mathrm{P}$ is also an important structural component of various biomolecules in plant cells, including adenosine triphosphate (ATP), phospholipids, DNA and RNA [2]. Although total P is abundant in soils, $\mathrm{P}$ is easily immobilized by soil components into unavailable forms that cannot be directly utilized by plants [3]. Thus, low phosphate (Pi) availability is considered a major limiting factor for crop growth, especially in acid soils that occupy about $50 \%$ of the world's arable land $[3,4]$. To obtain high yields in traditional agricultural systems, farmers need to apply excessive quantities of $\mathrm{P}$ fertilizer, potentially leading to soil deterioration and eutrophication problems [5]. Furthermore, $\mathrm{P}$ fertilizer is derived from mined phosphate rock, which is a finite resource that is slowly depleting [6]. Therefore, improving the absorption and utilization of soil P can be an effective way for increasing crop yield and reducing fertilizer $P$ application. Such improvements aim for the development of a more sustainable and environmentally sound agriculture.

To cope with low-P stress, plants have improved $\mathrm{Pi}$ uptake and homeostasis through a wide range of morphological, physiological and molecular changes, such as modifying root morphology and architecture, increasing secretion of organic acid and acid phosphatases, enhancing expression of high-affinity Pi transporters, developing symbioses with arbuscular mycorrhizal fungi, and regulating complex P signaling networks in plant cells $[7,8]$. It has been well demonstrated that plants display plasticity in root growth under P deficiency by changing root morphology and architecture, and thus increasing acquisition of $\mathrm{P}$ from the soil $[9,10]$. For example, increase in root length and root/shoot ratio is observed in maize (Zea mays) [11], faba bean (Vicia faba) [12], rapeseed (Brassica napus) and wheat (Triticum aestivum) [13] in response to low P supply. Furthermore, acid phosphatase activities are up-regulated by $\mathrm{Pi}$ deprivation in many plants, such as rice (Oryza sativa), soybean (Glycine max) and chickpea (Cicer arietinum), which could contribute to increased organic P utilization [14-16].

To date, a variety of $\mathrm{P}$ responsive genes have been identified to participate in Pi uptake and homeostasis $[8,17]$. For example, PHOSPHATE STARVATION RESPONSE
1 (AtPHR1) in Arabidopsis and OsPHR2 in rice, encoding the MYB transcription factor, are the central regulators involved in Pi signaling pathway [8]. AtPHR1 is demonstrated to regulate a set of Pi starvation induced (PSI) genes through binding to the P1BS cis element of target genes [18]. Furthermore, a negative regulatory role for protein containing the SYG1/PHO81/XPR1 (SPX) domain in rice is documented where OsSPX1 suppresses the transcripts of several PSI genes, such as $\mathrm{Pi}$ transporters (OsPT2 and OsPT6) and purple acid phosphatases (OsPAP10) [7]. A group of Pi transporters have been functionally characterized to be involved in Pi uptake and/or translocation in many plants; examples include: AtPT1 and AtPT2 from Arabidopsis [19, 20], OsPT1/9/10 from rice $[21,22]$ and GmPT5/7 from soybean [23, 24]. In addition, numerous purple acid phosphatase (PAP) homologues have also been demonstrated to function in Pi release from organic P, including AtPAP10/12/26 from Arabidopsis [25], OsPHY1 from rice [26], PvPAP1/3 from common bean (Phaseolus vulgaris) [27] and GmPAP14/33 from soybean [28, 29]. Furthermore, many other PSI genes have been identified to regulate root morphology and architecture, such as expansin 2 (GmEXPB2) and expansin 17 (OsEXPA17) [30, 31].

Stylosanthes guianensis (stylo) originates from the New World tropics, where acid soils are widely distributed [32]. Stylo is widely used in agricultural systems for livestock nutrition and soil improvement in South China $[33,34]$. Owing to its greater ability to adapt to plant growth limiting factors in acid soils, such as $\mathrm{P}$ deficiency, aluminum $(\mathrm{Al})$ and manganese $(\mathrm{Mn})$ toxicity, stylo has been regarded as an important tropical legume for dissecting its adaptive mechanisms to nutrient-poor acid soil [35-37]. A P-efficient stylo genotype has been found to display the capacity to use organic $\mathrm{P}$ as well as tolerance to high $\mathrm{Al}$ through enhanced root APase activity and modified root growth response, respectively [37-39]. Although the studies mentioned above provide some insights into the mechanisms of low-P tolerance in stylo, little is known about those associated with differential gene expression patterns. Certainly, the overall changes in expression profile of PSI genes in stylo roots have not been documented, which can be potentially used as candidate genes for breeding stylo varieties with high level of tolerance to low $\mathrm{P}$ in acid soils. Accordingly, the effects of $\mathrm{P}$ deficiency on dry mass production, $\mathrm{P}$ concentration 
and APase activities of two stylo cultivars, 'RY2' and 'RY5', were analyzed in this study. Genome-wide transcriptomic analysis of stylo roots in response to P deficiency was further conducted using RNA-seq and the molecular mechanisms underlying adaptation of stylo to low-P stress are suggested.

\section{Results}

\section{Characterization of low-P tolerance in two stylo cultivars}

In this study, two stylo cultivars ('RY2' and 'RY5') were subjected to 0,100 and $250 \mu \mathrm{M} \mathrm{KH_{2 }} \mathrm{PO}_{4}$ as low (Pi starvation), moderate and high $\mathrm{P}$ supply treatments, respectively, for $21 \mathrm{~d}$ under hydroponic conditions. Results showed that both plant height and leaf number of the two cultivars tested were significantly affected by $\mathrm{P}$ treatments. Compared to the high $\mathrm{P}(250 \mu \mathrm{M} \mathrm{P})$ treatment, low $\mathrm{P}$ availability resulted in decreased plant height and leaf number of both cultivars, especially under low $\mathrm{P}(0$ $\mu \mathrm{M}$ P) treatment (Fig. 1). The values of relative decrease rates of plant height and leaf number were 39.5 and $47.4 \%$ in RY5, and were 32.8 and $38.5 \%$ in RY2 under 0 $\mu \mathrm{M}$ P treatment compared to those under high $\mathrm{P}$ (250 $\mu \mathrm{M})$ application (Fig. 1b and c, Additional file 1). Similarly, compared to $250 \mu \mathrm{M}$ P treatment, shoot and root dry weight were decreased by 38.4-66.5\% in RY5 and 22.6-58.9\% in RY2 with $0 \mu \mathrm{M} P$ treatment (Fig. $2 \mathrm{a}$ and b). Furthermore, the relative decrease rates of shoot and root dry weight of RY5 were significantly higher than those of RY2 under $0 \mu \mathrm{M}$ P condition (Additional file 1). Similar to the results of shoot and root dry weight, low $\mathrm{P}$ availability resulted in less $\mathrm{P}$ accumulation in shoots and roots of the two cultivars. P concentrations in shoots and roots were decreased by $82.0-87.5 \%$ in RY5 and $83.7-88.9 \%$ in RY2 with $0 \mu \mathrm{M}$ P treatment, compared to those in 250 $\mu \mathrm{M} P$ treatment (Fig. $2 \mathrm{c}$ and d).

In addition, $\mathrm{P}$ acquisition and utilization efficiencies of the two cultivars evaluated were markedly influenced by P availability (Fig. 3). P acquisition efficiency of both cultivars was significantly increased by $\mathrm{P}$ supply in the solution. It was notable that $\mathrm{P}$ acquisition efficiency was higher in RY2 than in RY5 by more than 100.3, 84.7 and $102.7 \%$ under $0,100 \mu \mathrm{M}$ and $250 \mu \mathrm{M}$ P treatments, respectively (Fig. 3a). In contrast, P utilization efficiency of the two cultivars was decreased by an increase in $\mathrm{P}$ supply, and P utilization efficiency of RY2 was similar to that of RY5 under the same P treatment (Fig. 3b). These results together show that stylo cultivar RY2 is more tolerant to low-P stress compared to RY5.
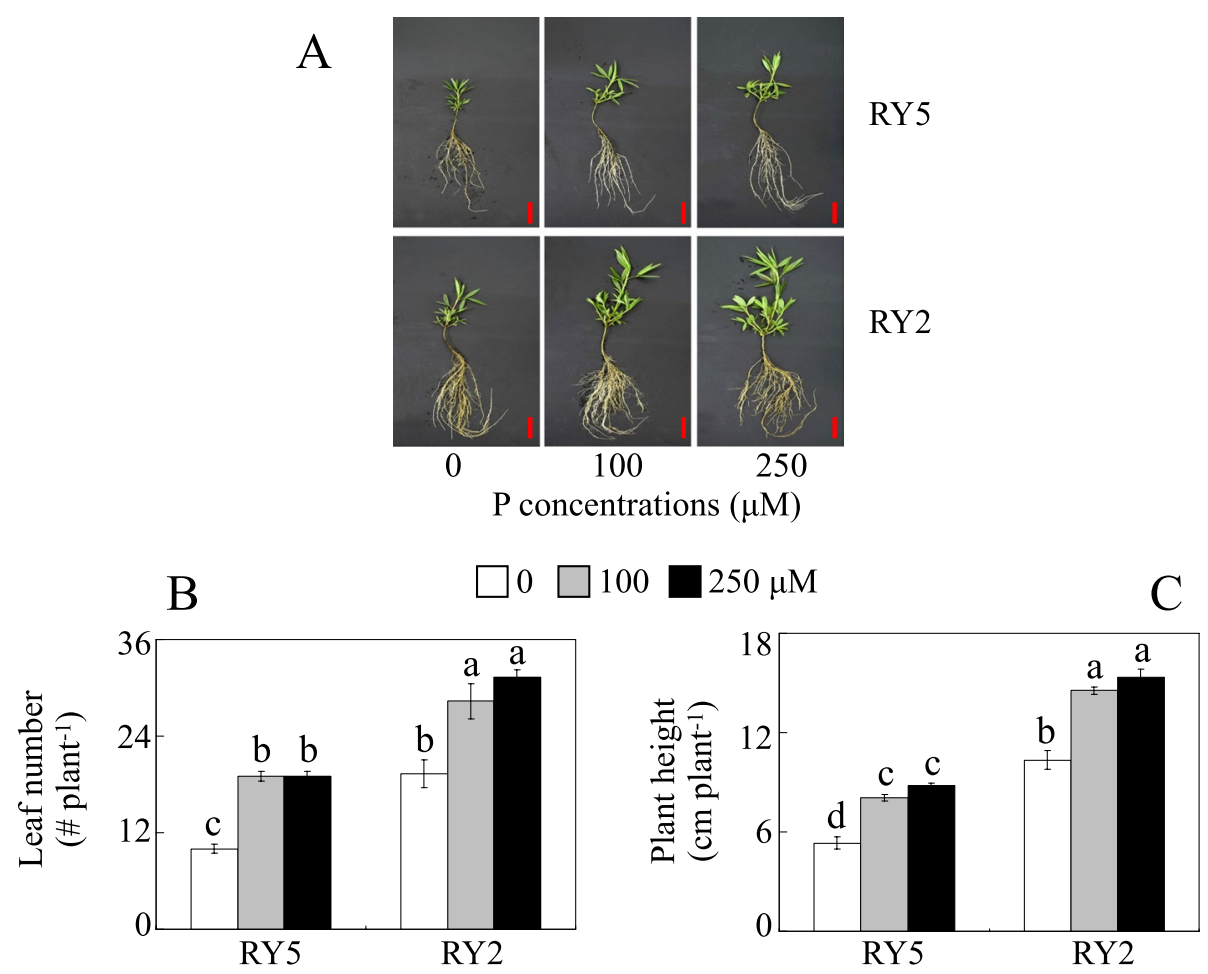

Fig. 1 Stylo growth under different P levels. a Growth performance of stylo. b Plant height. c Leaf number. Fourteen-day-old stylo seedlings were subjected to 0,100 and $250 \mu \mathrm{M} \mathrm{KH}_{2} \mathrm{PO}_{4}$ as low (Pi deprivation), moderate and high P supply treatments for $21 \mathrm{~d}$, respectively. Each bar represents the mean of three independent replicates with standard error (SE). Different letters indicate significant differences among $P$ treatments at $P<0.05$. $\mathrm{Bar}=5 \mathrm{~cm}$ 


\section{$0 \square 100 \square 250 \mu \mathrm{M}$}
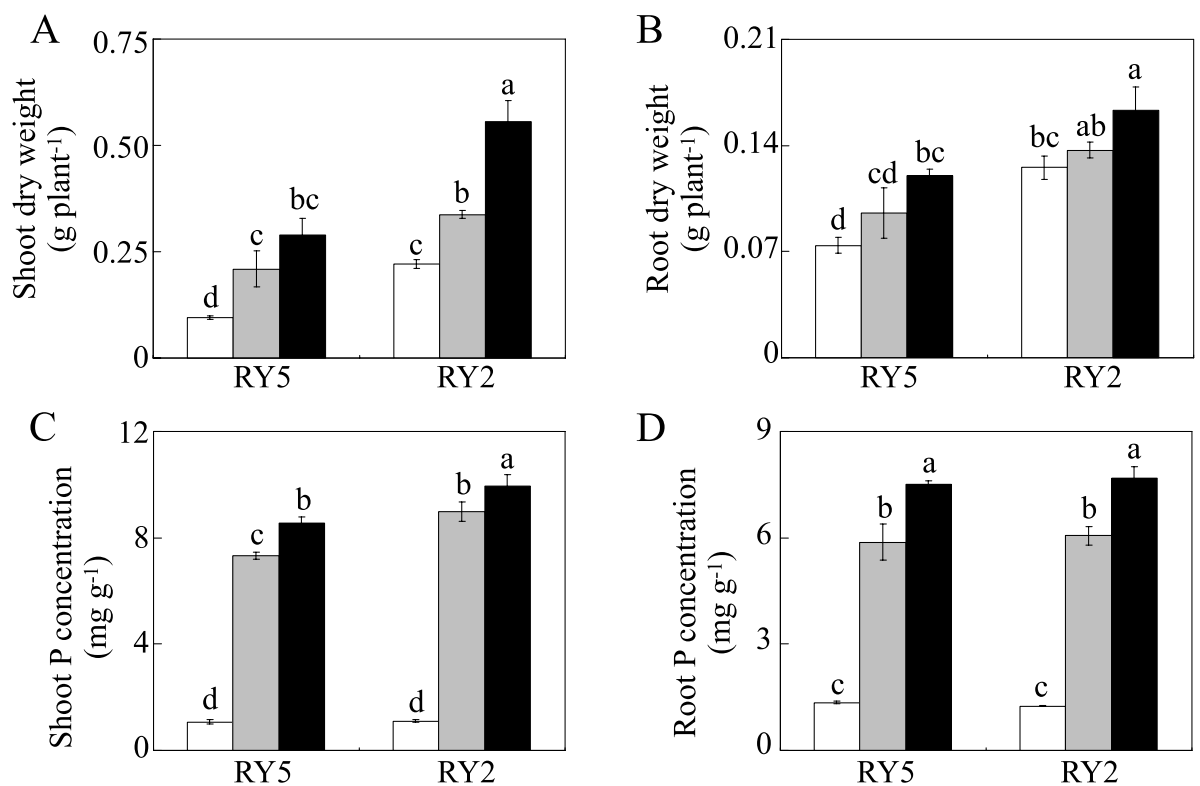

Fig. 2 Plant dry weight and $P$ concentration of stylo at different $P$ treatments. a Shoot dry weight. b Root dry weight. $\mathbf{c} P$ concentration in shoot. $\mathbf{d}$ $\mathrm{P}$ concentration in root. Fourteen-day-old stylo seedlings were subjected to 0, 100 and $250 \mu \mathrm{M} \mathrm{KH_{2 }} \mathrm{PO}_{4}$ as low (Pi deprivation), moderate and high $P$ supply treatments for $21 \mathrm{~d}$, respectively. Each bar represents the mean of three independent replicates with standard error (SE). Different letters indicate significant differences among $P$ treatments at $P<0.05$

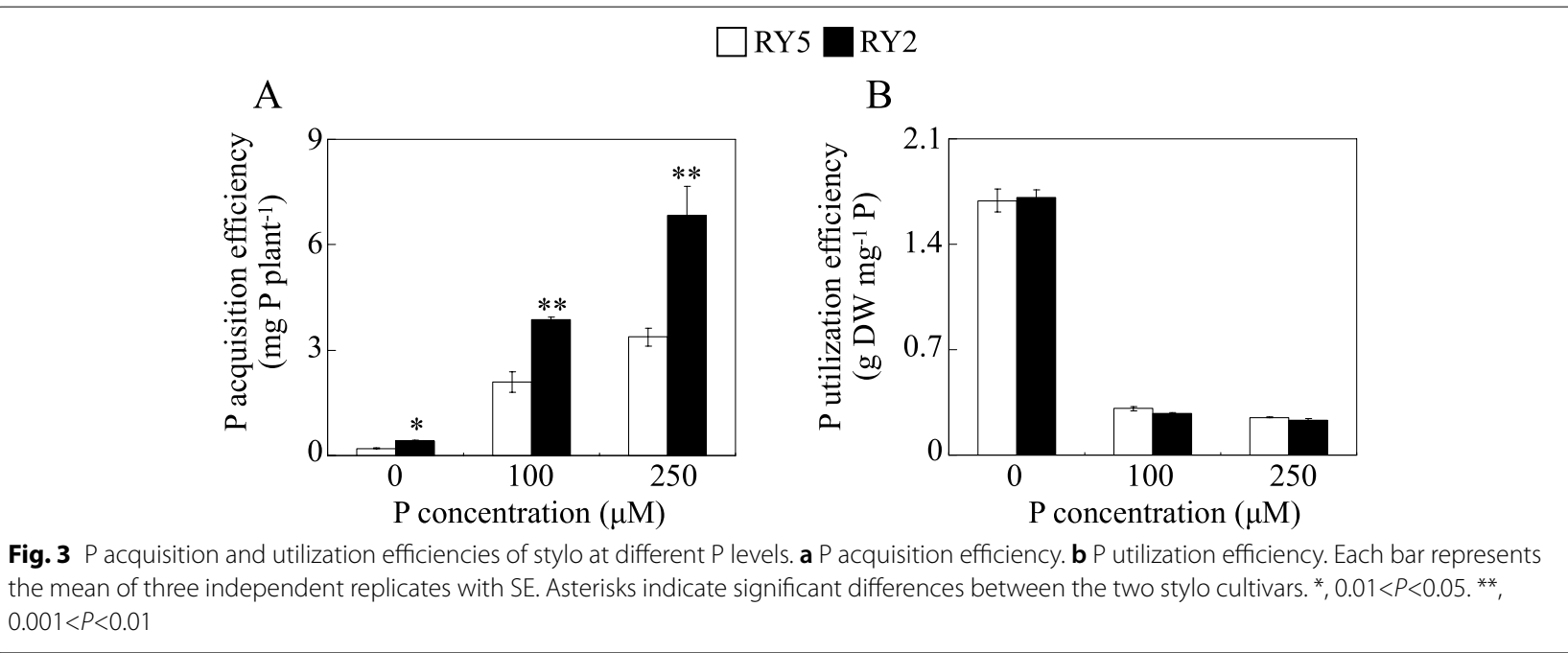

\section{Changes of root morphology and APase activities in response to $\mathrm{Pi}$ starvation}

Root morphology was subsequently analyzed from the response of stylo to P deficiency. As shown in Fig. 4, both total root length and lateral root length declined in the two cultivars under 0 and $100 \mu \mathrm{M}$ P treatments compared to high $\mathrm{P}$ application, but no significant differences were observed in the relative decrease rates of total root length and lateral root length between the two cultivars. Interestingly, total root length, lateral root length and root surface area in RY2 were 138.3$169.4,152.9-198.9$ and 116.6-144.8\% higher than those in RY5 under 0 and $100 \mu \mathrm{M}$ P treatments, respectively (Fig. 4). 


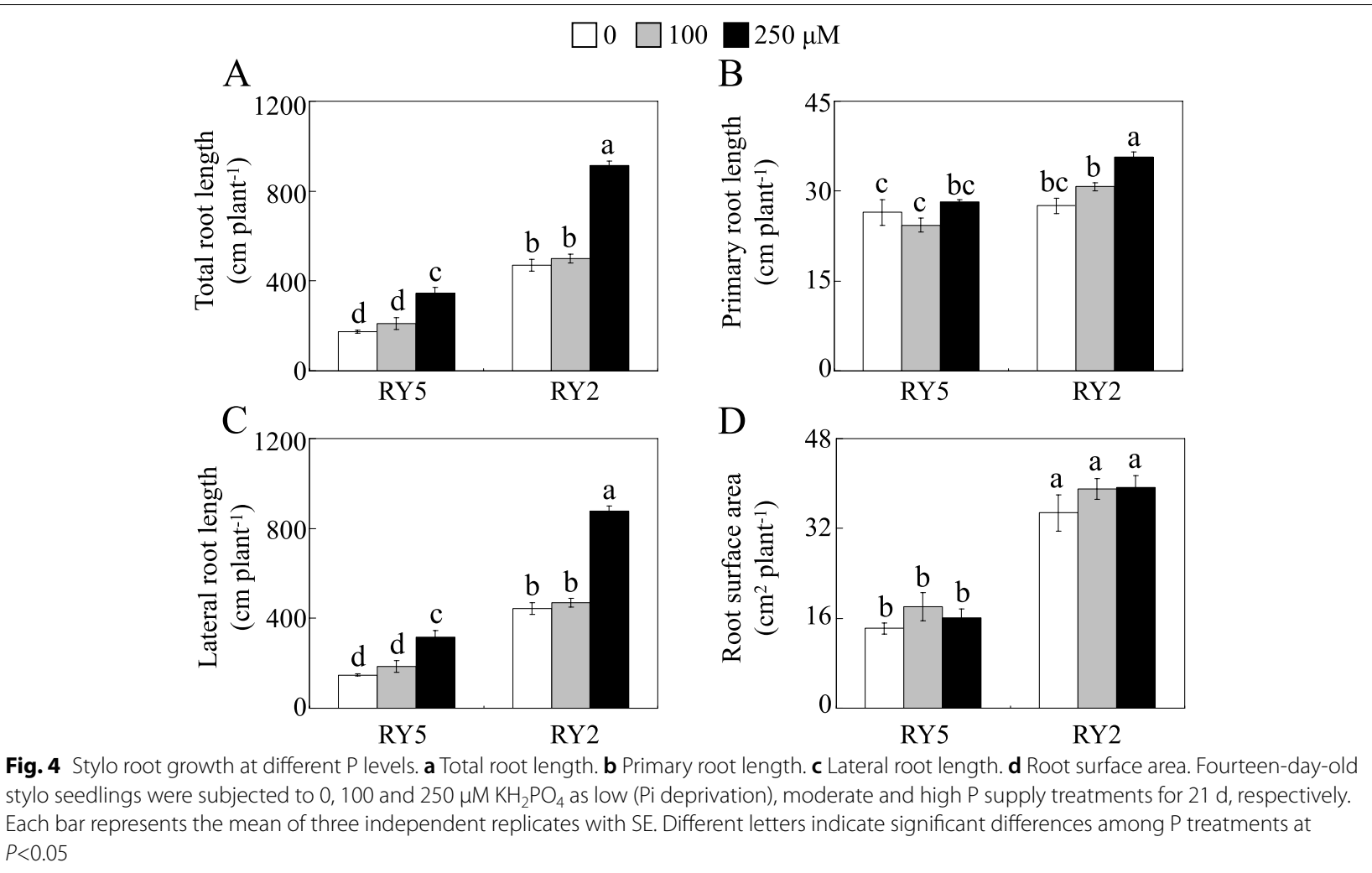

As increasing activity of APase is considered to be beneficial for plants in improving organic P utilization, APase activities in leaf and root of stylo under different $P$ treatments were further assayed. Compared to $250 \mu \mathrm{M} \mathrm{P}$, leaf and root APase activities were significantly increased by $0 \mu \mathrm{M}$ P treatment in both stylo cultivars (Fig. 5). Leaf APase activities in RY5 and RY2 respectively increased by 66.9 and $83.3 \%$ under $0 \mu \mathrm{M}$ P treatment compared to $250 \mu \mathrm{M}$ P application. Root APase activities in RY5 and RY2 were 31.7 and $135.8 \%$ greater under $0 \mu \mathrm{M}$ P treatment compared to $250 \mu \mathrm{M} \mathrm{P}$ application (Fig. 5). Furthermore, leaf and root APase activities in RY2 were about 22.8 and $30.3 \%$, respectively, higher than those in RY5 under $0 \mu \mathrm{M}$ P condition (Fig. 5).

\section{$\square 0 \square 100 \square 250 \mu \mathrm{M}$}
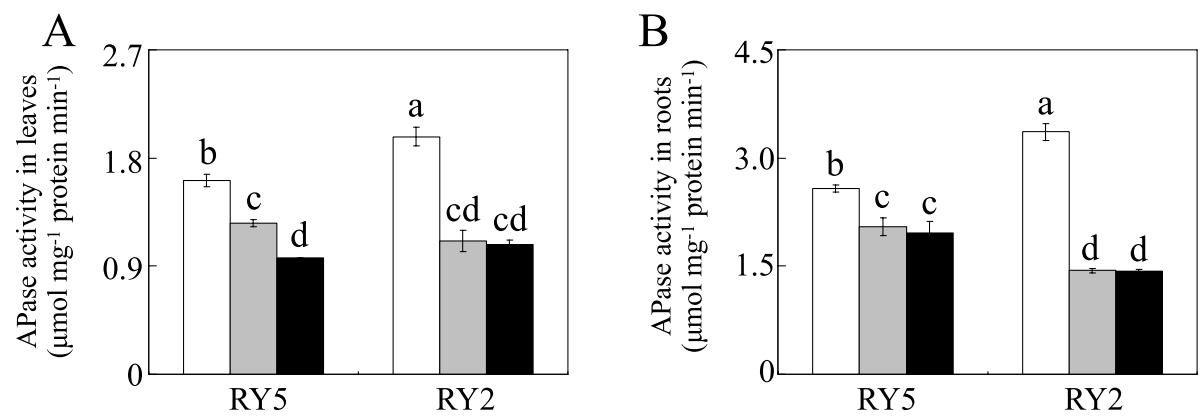

Fig. 5 Determination of APase activities. a Leaf APase activity. b Root APase activity. Fourteen-day-old stylo seedlings were subjected to 0, 100 and $250 \mathrm{\mu M} \mathrm{KH}_{2} \mathrm{PO}_{4}$ as low (Pi deprivation), moderate and high P supply treatments for $21 \mathrm{~d}$, respectively. Each bar represents the mean of three independent replicates with SE. Different letters indicate significant differences among $P$ treatments at $P<0.05$ 


\section{Transcriptomic changes in stylo roots in response to $\mathrm{Pi}$ starvation}

To further investigate the global expression profile of $\mathrm{Pi}$ starvation responsive genes in stylo roots, transcriptomic analysis of the low-P tolerant stylo cultivar RY2 at 0 (LP) and $250(\mathrm{HP}) \mu \mathrm{M} \mathrm{KH_{2 }} \mathrm{PO}_{4}$ supply treatments was conducted, which resulted in an average of 54.1 and 42.5 million clean reads in the libraries of stylo roots under LP and HP treatments, respectively (Additional file 2). From all samples, de novo assembly of the reads generated 326,640 transcripts and 173,014 unigenes (Additional file 2). The mean lengths of transcripts and unigenes were 787 and 1,243 bp, respectively (Additional file 2). A total of 8,348 genes with $\mid \log _{2}$ (fold change) $\mid \geq 1$ and $q<0.05$ were considered as differentially expressed genes (DEGs) in stylo roots from the two $\mathrm{P}$ treatments (Additional file 3). Among them, 3,707 and 4,641 genes were upregulated and down-regulated by $\mathrm{Pi}$ starvation in stylo roots, respectively (Additional file 3). Subsequently, a hierarchical clustering of all DEGs was generated to show the overview of the transcriptomic profiles (Additional file 4). The DEGs were clustered into three main clusters under the two P treatments (Additional file 4). Cluster 1 included both the up-regulated and down-regulated DEGs, while the expression levels of DEGs in clusters 2 and 3 were decreased and increased by LP treatment, respectively, compared to the HP treatment (Additional file 4).

Gene Ontology (GO) analysis showed that the identified DEGs can be classified into biological processes (BP), cellular components (CC) and molecular function (MF), which included 20, 4 and 12 GO terms, respectively
(Fig. 6a). Among the BP group, single-organism metabolic process, oxidation-reduction process, protein modification process, phosphorus metabolic process, transmembrane transport, protein phosphorylation and lipid metabolic process were the main terms (Fig. 6a). The dominant terms in CC contained intrinsic component of membrane, integral component of membrane, melanosome and pigment granule (Fig. 6a). Among the MF group, catalytic activity, ion binding, transferase activity, oxidoreductase activity, kinase activity, transporter activity and protein kinase activity were the major terms (Fig. 6a). Furthermore, the identified DEGs were analyzed via the Kyoto Encyclopedia of Genes and Genomes (KEGG) functional enrichment. There were 25 significantly enriched KEGG pathways. Among them, plant hormone signal transduction, phenylpropanoid biosynthesis, starch and sucrose metabolism, glycerophospholipid metabolism, glycerolipid metabolism, alanine, aspartate and glutamate metabolism, cyanoamino acid metabolism, tyrosine metabolism, circadian rhythmplant and inositol phosphate metabolism were the most dominant KEGG pathways (Fig. 6b).

\section{Transporters in response to low $\mathbf{P}$ availability}

A total of 279 DEGs encoding different kinds of transporters were enriched based on GO analysis (Additional file 5). The most significant enriched transporter genes were classified into $\mathrm{ABC}$ transporter, nitrate transporter, dicarboxylate transporter, sulfate transporter and $\mathrm{Pi}$ transporter (Fig. 7 and Additional file 5). For example, 43 genes were identified as $\mathrm{ABC}$ transporter, including 24 up-regulated and 19 down-regulated genes (Fig. 7 and

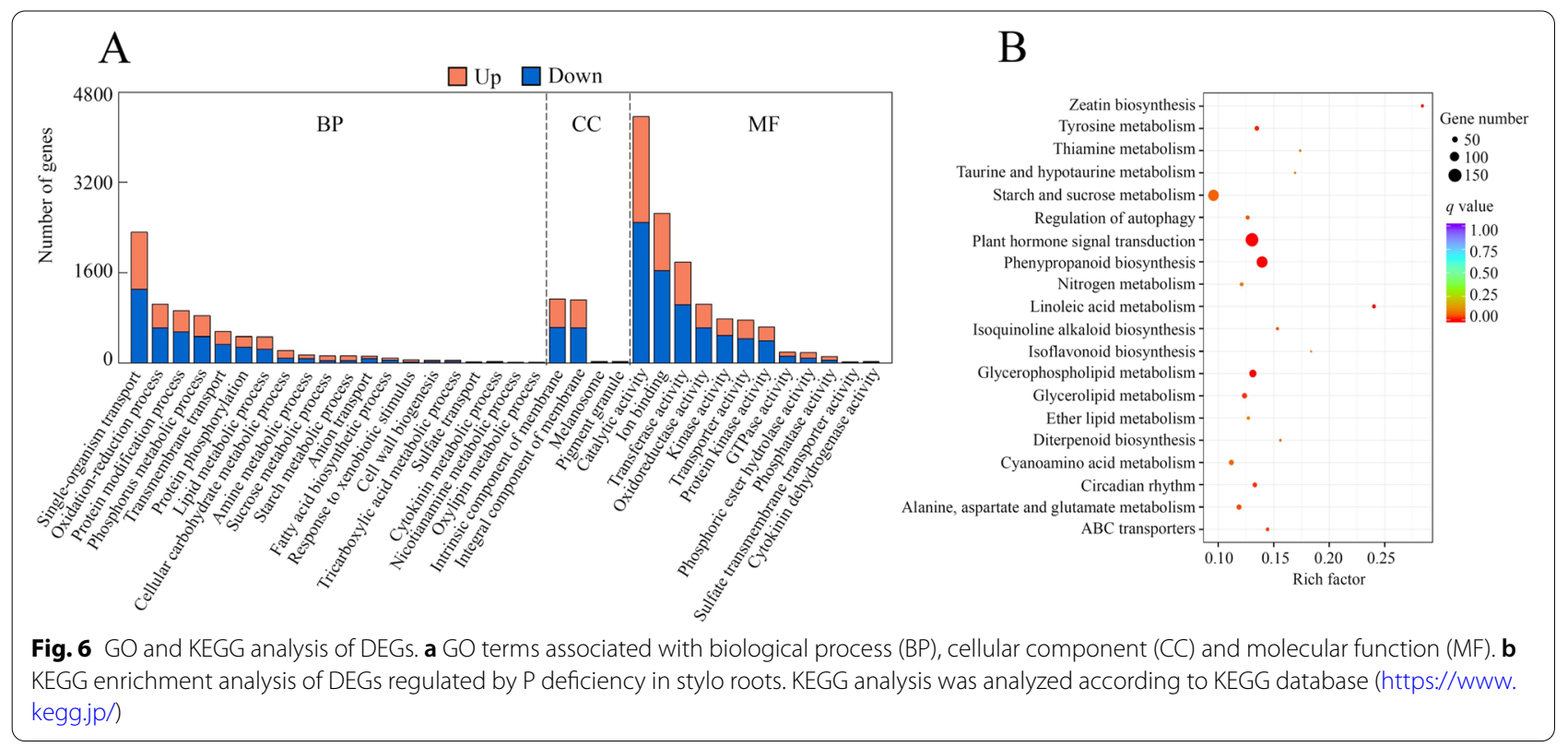




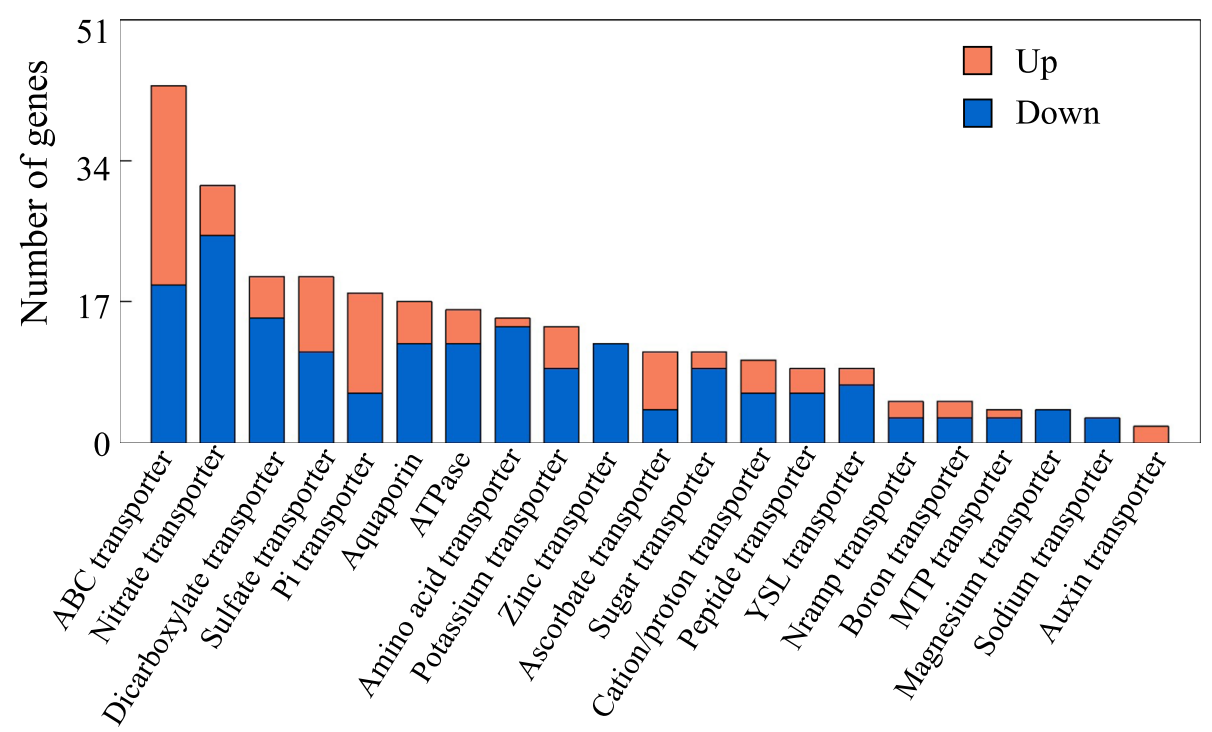

Fig. 7 DEGs related to transporters in stylo roots. X-and Y-axis indicate different kinds of transporters and their corresponding number, respectively

Additional file 5). The transcripts of $A B C$ transporter $D$ family member 1, ABC transporter B family member 26 , $A B C$ transporter $B$ family member 19 and $A B C$ transporter $C$ family member 3 were induced by low-P stress, while $A B C$ transporter ATP-binding protein was completely suppressed (Additional file 5 ). Interestingly, 25 out of 31 genes encoding nitrate transporter were downregulated by $\mathrm{P}$ deficiency, but six genes were enhanced, such as NRT1/PTR FAMILY 8.3, nitrate transporter 1.4-like, putative nitrate excretion transporter 2, probable peptide/nitrate transporter At5g62680-like, and two probable nitrate transporter At1g68570 (Additional file 5). Among the $18 \mathrm{DEGs}$ belonging to the putative Pi transporter, 12 and 6 genes were up-regulated and downregulated by Pi starvation, respectively (Fig. 8). For example, transcripts of two inorganic phosphate transporter 1-4-like, one xylulose 5-phosphate/phosphate translocator and one inorganic phosphate transporter 2-1 were significantly induced by low $\mathrm{P}$ treatment (Additional file 5). In addition, a set of 20 genes enriched in dicarboxylate transporter were found to be mainly encoding for multidrug and toxin extrusion (MATE) and aluminumactivated malate transporter (ALMT) (Additional file 5). Among them, five MATE homologues, including one MATE efflux family protein 5-like, one MATE efflux family protein 8-like, two MATE efflux family protein 5 and one MATE efflux family protein DTX1-like, were up-regulated by $\mathrm{P}$ deficiency, and three genes encoding ALMT family protein were down-regulated, such as aluminumactivated malate transporter 10-like, aluminum-activated malate transporter 9-like and aluminum-activated malate transporter 2 (Additional file 5).
DEGs related to phosphatases and root growth responding to $P$ deficiency

A total of 116 DEGs were predicted to encode phosphatases according to $\mathrm{GO}$ analysis, including 68 up-regulated genes and 48 down-regulated genes (Additional file 6). Among them, a group of 23 genes were related to putative purple acid phosphatases (PAP) (Fig. 9 and Additional file 6). As shown in Fig. 9, 21 PAP homologues were up-regulated by $\mathrm{P}$ deficiency, and only two PAPS were down-regulated in stylo roots. Among them, DEGs, such as purple acid phosphatase 22-like, purple acid phosphatase 2-like and purple acid phosphatase 23-like homologues were induced by Pi starvation, while purple acid phosphatase 8-like was suppressed (Fig. 9).

In addition, twelve genes related to root growth were also found to be regulated by P deficiency, including five up-regulated and seven down-regulated genes. Among them, one expansin-A13 and two expansin-B1-like genes were up-regulated and down-regulated by $\mathrm{P}$ deficiency, respectively (Additional file 7).

\section{Potential transcription factors and regulators involved in $\mathrm{Pi}$ signaling}

A total of 282 DEGs were annotated as transcription factors (TFs) (Fig. 10 and Additional file 8). Among them, genes encoding zinc finger (ZF) TFs were the largest group, containing 29 up-regulated and 40 down-regulated genes. The other TFs included genes encoding MYB (41), bHLH (32), NAM (27), AP2 (26), HSF (25), WRKY (19), Homeobox (17), SCARECROW (6), bZIP (6), ARF (5), K-box (5) and TCP (4) families (Fig. 10). Among the ZF TFs, six genes were induced and four genes were 


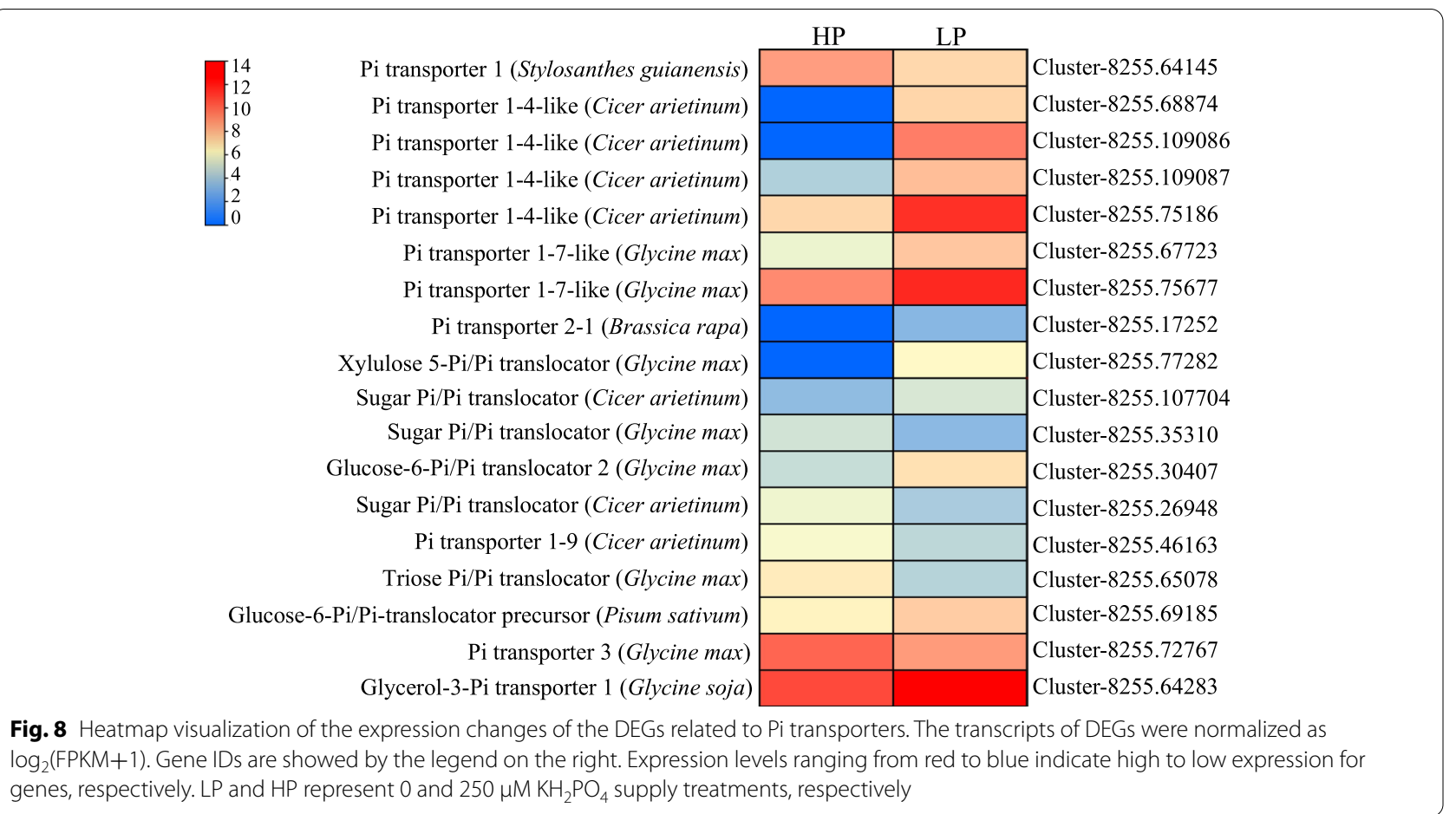

\begin{tabular}{|c|c|c|c|}
\hline & HP & LP & \multirow[b]{2}{*}{ Cluster-8255.16873 } \\
\hline Purple acid phosphatase 2-like (Glycine max) & & & \\
\hline Purple acid phosphatase 2-like (Glycine max) & & & Cluster-8255.17646 \\
\hline Purple acid phosphatase 2-like (Glycine max) & & & Cluster-8255.114464 \\
\hline Purple acid phosphatase 2-like (Glycine max) & & & Cluster-8255.17137 \\
\hline Purple acid phosphatase 2-like (Glycine max) & & & $\begin{array}{l}\text { Cluster- } 8255.114665 \\
\text { Cluster- } 825583559\end{array}$ \\
\hline Purple acid phosphatase 8-like (Glycine max) & & & Cluster- 8255.83559 \\
\hline Purple acid phosphatase 8-like (Glycine max) & & & Cluster-8255.92531 \\
\hline Purple acid phosphatase 8-like (Glycine max) & & & Cluster- 8255.83560 \\
\hline Purple acid phosphatase 22-like (Glycine max) & & & Cluster-8255.111686 \\
\hline Purple acid phosphatase 22-like (Glycine max) & & & Cluster-8255.22289 \\
\hline Purple acid phosphatase 22-like (Cicer arietinum) & & & Cluster-8255.23606 \\
\hline Purple acid phosphatase 22-like (Glycine max) & & & Cluster-8255.21809 \\
\hline Purple acid phosphatase 23-like (Glycine max) & & & \\
\hline Purple acid phosphatase 23-like (Glycine max) & & & Cluster-8255.26338 \\
\hline Purple acid phosphatase 23-like (Glycine max) & & & Cluster-8255.28900 \\
\hline Purple acid phosphatase 23-like (Glycine max) & & & Cluster-8255.110899 \\
\hline Purple acid phosphatase 23-like (Glycine max) & & & Cluster-8255.24194 \\
\hline Purple acid phosphatase 23-like (Glycine max) & & & Cluster-8255.31565 \\
\hline Inactive purple acid phosphatase 27-like precursor (Glycine max) & & & Cluster-8255.46686 \\
\hline Inactive purple acid phosphatase 27-like (Glycine max) & & & Cluster-8255.46688 \\
\hline Inactive purple acid phosphatase 27 (Glycine soja) & & & \\
\hline Purple acid phosphatase-like protein (Glycine max) & & & \multirow{2}{*}{$\begin{array}{l}\text { Cluster- } 8255.86848 \\
\text { Cluster- } 8255.85731\end{array}$} \\
\hline Purple acid phosphatase (Medicago truncatula) & & & \\
\hline $\begin{array}{l}\text { Fig. } 9 \text { Heatmap analysis of the DEGs associated with purple acid phosphatases. T } \\
\text { IDs are showed by the legend on the right. Expression levels ranging from red to } k \\
\text { HP represent } 0 \text { and } 250 \mu \mathrm{M} \mathrm{KH}_{2} \mathrm{PO}_{4} \text { supply treatments, respectively }\end{array}$ & & & $\begin{array}{l}\text { re normalized as } \log _{2}(F P K M+1) \text {. Gene } \\
\text { expression for genes, respectively. LP and }\end{array}$ \\
\hline
\end{tabular}

absolutely suppressed by P deficiency (Additional file 8). Furthermore, four ZF genes including zinc finger protein NUTCRACKER-like, zinc finger BED domain-containing protein RICESLEEPER 2-like, zinc finger CCCH domain protein and DHHC-type zinc finger protein were up-regulated by more than 6-fold under $\mathrm{P}$ deficiency, whereas 


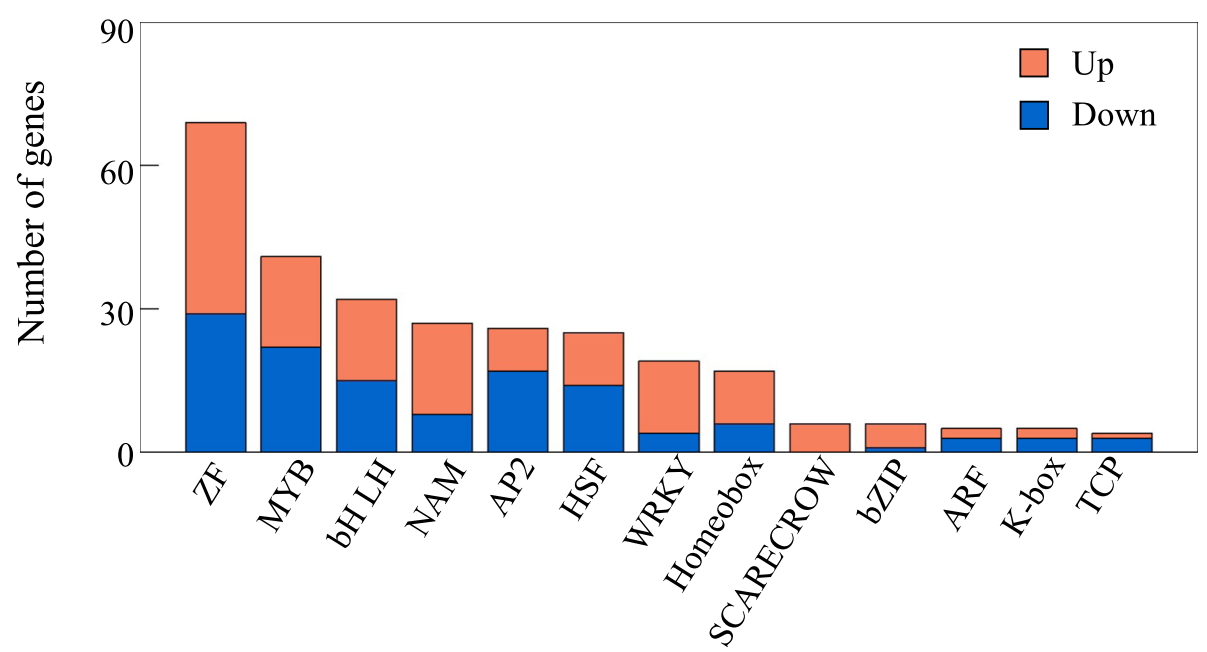

Fig. 10 DEGs related to transcription factors. X-and Y-axis indicate different kinds of TF and their corresponding number, respectively

zinc finger protein JACKDAW-like was suppressed by more than 6-fold under P deficiency (Additional file 8). There were 41 genes belonging to MYB TFs, including 22 up-regulated and 19 down-regulated genes. Among these MYB TFs, two PHR1-like homologues were downregulated by $\mathrm{P}$ deficiency (Additional file 8). Interestingly, a total of 63 TFs were predicted to be involved in plant hormone signal transduction, including genes associated with ethylene, auxin, abscisic acid and brassinosteroid signaling pathway (Additional file 9). In addition, genes encoding protein containing SPX domain were also found to be regulated by $\mathrm{P}$ deficiency. Among them, 9 out of 13 SPX homologues were up-regulated by more than 8 -fold under $\mathrm{P}$ deficiency, and the remaining four SPXs were down-regulated in stylo roots (Additional file 10).

Subsequently, the interaction networks were further constructed to explore the candidate TFs potentially involved in the regulation of genes related to transporters, phosphatase and root growth in stylo during $\mathrm{P}$ deficiency. Results showed that the interaction networks contained 147 edges with 58 nodes (Fig. 11). Among them, one gene encoding ATPase subunit 1 (Cluster-8255.74336) was regulated by seven TFs, including five homologues of heat shock protein (Cluster-8255.65169, Cluster-8255.66995, Cluster-8255.56180, Cluster-8255.106909 and Cluster-8255.92909) and two probable mediator of RNA polymerase II transcription subunit 37c-like (Cluster-8255.69596 and Cluster-8255.66276) (Fig. 11). One high-affinity nitrate transporter 3.1-like (Cluster-8255.67810) was found to be regulated by one TF belonging to WRKY family (Cluster-8255.60706). Interestingly, two root growth related genes, protein ROOT HAIR DEFECTIVE 3 homolog 1-like (Cluster-8255.68495) and protein ROOT HAIR
DEFECTIVE 3 homolog 2-like (Cluster-8255.28286), were both regulated by chaperone protein dnaJ (Cluster-8255.88810). Furthermore, heat shock $70 \mathrm{kDa}$ protein 16-like isoform X1 (Cluster-8255.92909) and heat shock protein 83 isoform X2 (Cluster-8255.66995), belonging to HSF family, were found to target to 21 and 20 genes in the interaction networks, respectively (Fig. 11). These results suggest the complex nature of regulatory networks of stylo in response to P deficiency.

\section{Analysis of RNA-seq data using quantitative real-time PCR (qRT-PCR)}

A total of 13 DEGs from the RNA-seq data, including 9 up-regulated and 4 down-regulated genes, were selected for qRT-PCR analysis in RY2 roots at two P levels. Results showed that the trends of transcripts of the tested genes based on qRT-PCR matched well with its corresponding expression presented in the RNA-seq data, as reflected by a significant correlation $\left(\mathrm{R}^{2}=0.811, P<0.01\right)$ (Additional file 11).

\section{Discussion}

$P$ deficiency influences numerous biological processes in crop plants, such as rice, soybean and wheat, markedly reducing crop yield [40-42]. In this study, differences in low-P tolerance were observed between the two stylo cultivars, and RY2 is identified as a low-P tolerant cultivar. Stylo RY2 exhibited lower rates of decrease in growth parameters than RY5 under low-P stress, especially for shoot and root dry weight (Figs. 1 and 2). Furthermore, $P$ acquisition efficiency of RY2 was higher than that of RY5 under the same P treatment (Fig. 3). It has been well demonstrated that changes in root system architecture increase $\mathrm{P}$ acquisition by plants from the soil, and these 


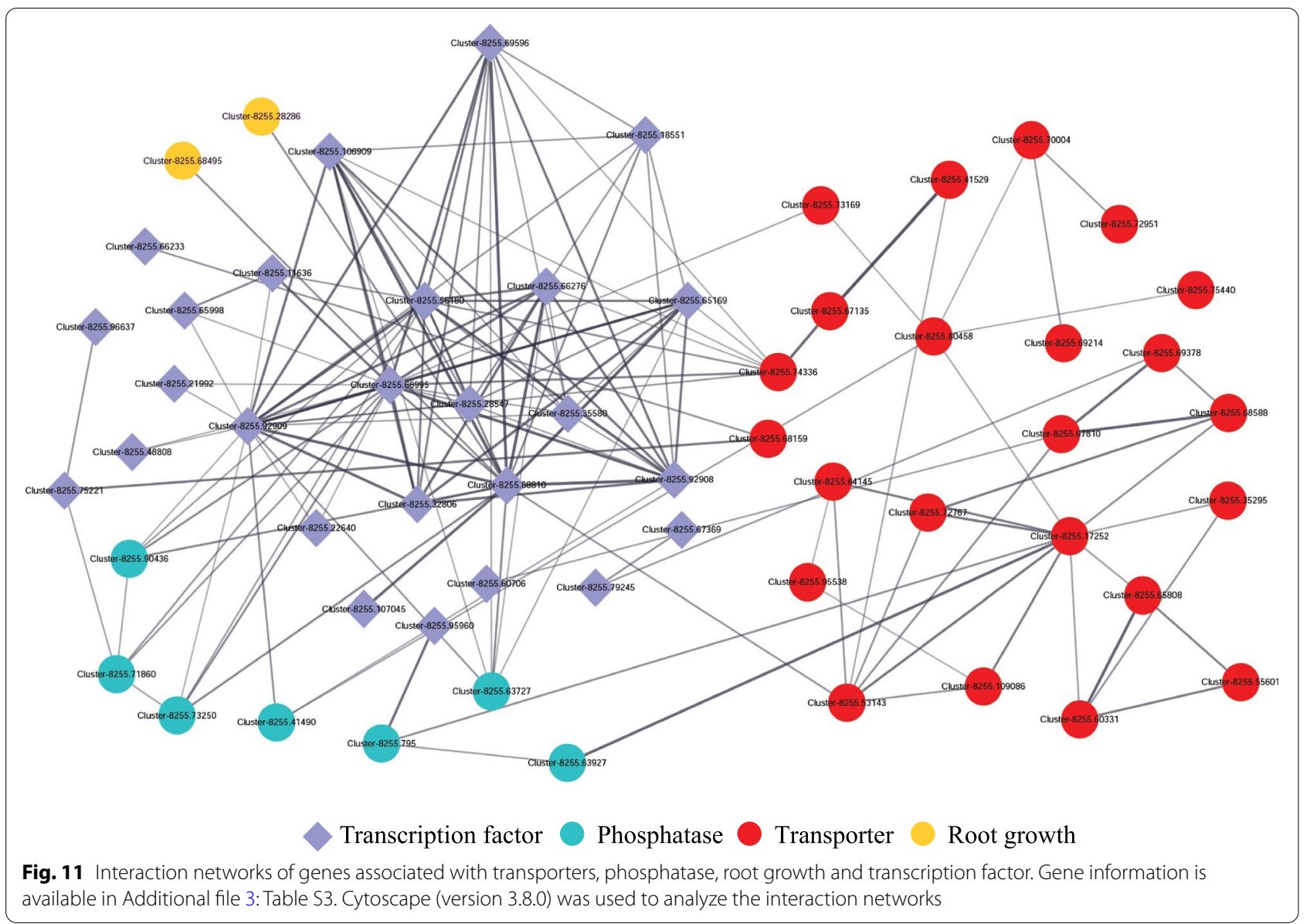

root traits include larger values of root biomass, root/ shoot ratio and root surface area in the topsoil [11-13]. For example, increases in root/shoot biomass ratio are observed in maize and wheat, while higher specific root length is found in rapeseed under low P supply, which are considered adaptive strategies beneficial for improving P acquisition [13]. Similarly, root growth parameters including total root length, lateral root length and root surface area, were higher in RY2 than those in RY5 under low-P stress (Fig. 4). Thus, the stylo cultivar RY2 is more tolerant to $\mathrm{P}$ deficiency probably through regulation of its root growth.

To elucidate the molecular mechanisms underlying the adaptation of stylo to $\mathrm{P}$ deficiency, overall transcriptome changes in roots of cultivar RY2 in response to P deficiency were investigated using RNA-seq analysis. Many of the identified DEGs were found to encode putative transporters, phosphatases and transcription factors that are associated with root growth, $\mathrm{Pi}$ acquisition and $\mathrm{Pi}$ homeostasis as well as Pi signaling. Among them, a group of DEGs were categorized as transporters, such as nitrate transporter, $\mathrm{Pi}$ transporter and dicarboxylate transporter (Additional file 5). Many genes encoding nitrate transporters were regulated by $\mathrm{P}$ deficiency, including six low P-enhanced nitrate transporter genes (Additional file 5). Regulation of genes encoding nitrate transporters by $\mathrm{P}$ deficiency has also been observed in Arabidopsis [43], rice [44] and soybean [45]. In addition to function in enhancing nitrogen $(\mathrm{N})$ use efficiency, overexpression of the high-affinity nitrate transporter, OsNRT2.3b, can increase $\mathrm{P}$ uptake and accumulation in rice through regulation of root growth and expression of PSI genes (e.g., OsPT2, OsPT8 and OsPHR2) [46]. Interestingly, four putative $P T$ homologues encoding inorganic phosphate transporter 1-4-like, two $P T$ genes encoding inorganic phosphate transporter 1-7-like and one member belonging to inorganic phosphate transporter 2-1 were up-regulated by $P$ deficiency in this study (Fig. 8). Numerous $P T$ homologues are found to be enhanced by $\mathrm{P}$ deficiency in soybean [23], rice [47] and Medicago (Medicago truncatula) [48]. For example, in Arabidopsis, the transcripts of two Pi transporters (Pht1;1 and Pht1;4) are significantly increased in low P-treated roots, which are involved in Pi uptake $[49,50]$. In rice, OsPT2 is up-regulated in both shoots and roots by low-P stress, and is found to be involved in $\mathrm{Pi}$ acquisition and the long-distance 
translocation of Pi from roots to shoots [51]. Therefore, these results suggest that the low $\mathrm{P}$ up-regulated nitrate transporter and $\mathrm{Pi}$ transporter can regulate $\mathrm{Pi}$ transport and Pi homeostasis in stylo as part of the underlying molecular mechanism of adaptation to P deficiency, which deserves further investigation.

As a large amount of soil $\mathrm{P}$ is poorly available for plants, one of the important strategies for increasing $\mathrm{P}$ mobilization and uptake is to stimulate the release of Pi from sparingly soluble $\mathrm{P}$ through secreted organic acids from root to rhizosphere [52]. Transporters responsible for organic acid transport, such as ALMT and MATE, have been well demonstrated to be participating in malate and citrate transport, respectively [52, 53]. Divergent expression patterns of ALMTS or MATEs are found in plants response to abiotic stresses, such as salt and proton stresses, $\mathrm{P}$ deficiency and $\mathrm{Al}$ toxicity [53-55]. In this study, the up-regulation of MATE homologues probably results in increasing citrate exudation from stylo roots in response to $\mathrm{P}$ deficiency, which can be supported by the observation of citrate secreted from RY2 roots under $P$ deficient condition [56]. As genes encoding putative malate transporter proteins were suppressed by $\mathrm{P}$ deficiency (Additional file 5), the MATE genes mediated citrate exudation are possibly involved in $\mathrm{P}$ mobilization in stylo, and their functions merit further characterization.

Enhancing transcription and activity of phosphatases is generally considered to be helpful for plants increasing $\mathrm{Pi}$ availability by hydrolyzed organic $\mathrm{P}$ to release $\mathrm{Pi}[37,38]$. A set of genes encoding phosphatases were found to be differentially expressed under two $P$ levels in this study (Additional file 6). Interestingly, 21 out of 23 PAP homologues, such as purple acid phosphatase 2-like, purple acid phosphatase 8-like, purple acid phosphatase 22-like, purple acid phosphatase 23-like and purple acid phosphatase 27-like, were up-regulated by $\mathrm{Pi}$ starvation in stylo roots; this was consistent with the increasing APase activity in stylo roots under P deficient treatment (Figs. 5 and 9). Similarly, 10 out of 26 PAP members in rice, 11 out of 29 PAPs in Arabidopsis, 23 out of 35 PAPs in soybean and 12 out of 25 PAPs in chickpea are known to be up-regulated by $\mathrm{P}$ deficiency, potentially participating in organic $P$ utilization $[15,57-59]$. Therefore, it is reasonable to assume that the Pi starvation-enhanced PAP homologues are possibly involved in organic $P$ utilization by stylo to cope with P deficiency.

Optimizing root growth parameters, such as total root length, lateral root branching and root hair density, is particularly important for plants to increase $\mathrm{Pi}$ acquisition. A variety of genes have been reported to be responsible for root growth, including expansin genes. For example, GmEXPB2, an expansin gene in soybean, is mainly expressed in roots and is induced by $\mathrm{P}$ deficiency; functional analysis demonstrates that GmEXPB2 is involved in root cell division and root hair elongation, thereby contributing to plant growth and $\mathrm{P}$ uptake [30]. In this study, three expansin homologues were found to be differentially regulated by $\mathrm{P}$ deficiency (Additional file 7). A similar result has been recently reported [60] in which seven expansin genes are found to be regulated by $\mathrm{P}$ deficiency in stylo, including six up-regulated and one down-regulated genes and these genes are suggested to be involved in stylo root growth under Pi deprivation. Therefore, these results suggest that some of the stylo expansin genes may be participating in modifying root growth adaptation to $\mathrm{P}$ deficiency, but their exact involvement needs to be further studied.

The adaptive strategies employed by plants to maintain cellular Pi homeostasis are generally regulated by signaling network involving transcription factors and other potential regulators [18]. Several TFs have been demonstrated as key participants in Pi signaling pathways, such as members belonging to MYB, WRKY, bHLH and ARF families, which were also identified in this study (Fig. 10 and Additional file 8). For example, PHR1 belonging to the MYB family, is the most wellcharacterized TF and also a central integrator in transcriptional regulation of $\mathrm{Pi}$ starvation responses (PSR). A variety of PHR1 homologues with similar functions in regulating Pi homeostasis have been identified in many plants, such as AtPHR1, PHR1-like1 (PHL1) and PHL2 in Arabidopsis, OsPHR1/2/3/4 in rice, GmPHR25 in soybean and PvPHR1 in common bean, and most of these PHR1 homologues are up-regulated by $\mathrm{P}$ deficiency [8, 61-64]. In this study, a total of 41 DEGs were identified as TFs belonging to MYB family. Among them, two PHR1-like homologues were found to be down-regulated by $P$ deficiency (Additional file 8 ), suggesting that there are other regulatory mechanisms mediated by PHR1 in the adaptation of stylo to $\mathrm{P}$ deficiency in soil, which are probably different from those well-known PHR1 members identified in other plants. In addition, a set of TFs belonging to WRKY family were found to be regulated by $\mathrm{P}$ deficiency in stylo roots (Additional file 8). WRKY is an important TF involved in Pi signaling pathways. It has been reported that WRKY6 and WRKY75 in Arabidopsis are involved in regulating PSI genes, such as genes encoding phosphatases and high-affinity Pi transporters, controlling $\mathrm{Pi}$ homeostasis and root growth in response to $P$ deficiency $[65,66]$. Interestingly, in this study, one high-affinity nitrate transporter 3.1-like (Cluster-8255.67810) was found to be regulated by one WRKY member (Cluster-8255.60706) (Fig. 11), suggesting a possible dual role for these genes in regulation of $\mathrm{Pi}$ as well as $\mathrm{N}$ homeostasis. 
In this study, 13 DEGs related to the putative SPX domain-containing proteins involved in $\mathrm{Pi}$ signaling pathways were found to be regulated by $\mathrm{P}$ deficiency (Additional file 10). Similar results are also found in soybean where GmSPXs exhibited differential regulation by $\mathrm{P}$ deficiency in soybean root [67]. SPX domain-containing proteins have been well characterized to be the important components in Pi signaling pathway in Arabidopsis, rice and soybean [67-69]. For example, OsSPX4 acts as a negative regulator of OsPHR2. OsSPX4 could interact with OsPHR2 through inhibition of the binding of OsPHR2 to its target genes under Pi sufficient condition, whereas OsSPX4 can be degraded through the $26 \mathrm{~S}$ proteasome pathway under Pi deficiency [70]. Therefore, the identified various TFs and regulators from this study suggest a complex response mechanism of stylo to P deficiency, which in turn contributes to maintain cellular Pi homeostasis.

\section{Conclusion}

This study revealed that $\mathrm{P}$ deficiency resulted in reduction of stylo growth, and stylo cultivar RY2 exhibited higher low-P tolerance than RY5. Numerous DEGs were identified through transcriptomic analysis of RY2 roots under P deficiency. Furthermore, DEGs encoding putative transporters, phosphatases and transcription factors suggested the underlying mechanisms of adaptation of stylo to P deficiency. The low-P tolerance of RY2 is probably manifested through regulation of root growth, $\mathrm{Pi}$ acquisition and cellular Pi homeostasis as well as $\mathrm{Pi}$ signaling pathway. The identified genes can be potentially used to design a breeding strategy for developing P-efficient stylo cultivars to grow on acid soils in the tropics.

\section{Methods}

\section{Plant growth and treatments}

In this study, two stylo (Stylosanthes guianensis) cultivars, 'RY2' and 'RY5', were used, which were widely grown in South China [33]. The stylo seeds were provided by the Institute of Tropical Crop Genetic Resources (TCGRI), Chinese Academy of Tropical Agricultural Sciences (CATAS), Hainan, China. Experiments were performed in a greenhouse at temperatures of $25^{\circ} \mathrm{C}$ to $32{ }^{\circ} \mathrm{C}$ under natural sunlight with a photoperiod of about $13 \mathrm{~h}$ at the TCGRI, CATAS, Hainan, China $\left(19^{\circ} 30^{\prime} \mathrm{N}, 109^{\circ} 30^{\prime} \mathrm{E}\right)$. Seeds were germinated for $3 \mathrm{~d}$, and stylo seedlings were then transferred to a modified Hoagland nutrient solution containing $250 \mu \mathrm{M} \mathrm{KH_{2 }} \mathrm{PO}_{4}$ for $14 \mathrm{~d}$ as previously described [71]. After that, seedlings were separately transplanted into nutrient solution supplied with 0,100 and $250 \mu \mathrm{M} \mathrm{KH}_{2} \mathrm{PO}_{4}$, which were regarded as low (Pi deprivation), moderate and high $\mathrm{P}$ supply treatments, respectively. The nutrient solution was adjusted to a $\mathrm{pH}$ value of 5.8 and refreshed weekly. After $21 \mathrm{~d}$ of P treatments, shoots and roots were separately harvested for further analysis. An individual hydroponic box containing three seedlings of each stylo cultivar was set as one biological replicate. Each treatment included three biological replicates.

\section{Determination of root morphology and $\mathrm{P}$ concentration}

Plant fresh roots were scanned using an Epson 12000XL scanner (Epson, Japan) with a resolution of $300 \mathrm{dpi}$, and the obtained image was saved as JEPG format. Total root length, root surface area and root volume were analyzed with WinRhizo Pro software (Regent Instruments Inc., Quebec, Canada). After that, shoot and root samples were oven dried at $75{ }^{\circ} \mathrm{C}$ for $7 \mathrm{~d}$, and the dry mass of shoots and roots was further determined. For P concentration analysis, approximately $0.07 \mathrm{~g}$ dry samples were burned to ash at $600{ }^{\circ} \mathrm{C}$ in a muffle furnace. The sample of ash was absolutely dissolved in $100 \mathrm{mM} \mathrm{HCl}$, and the supernatant was then used for P concentration analysis as previously described [72].

\section{Analysis of APase activity}

APase activities in stylo leaf and root were analyzed as previously described [38] with some modification. Approximately $0.15 \mathrm{~g}$ of leaf and root samples were ground in $1.5 \mathrm{~mL}$ of $45 \mathrm{mM} \mathrm{Na}$-acetate buffer $(\mathrm{pH}$ 5.0) at $4{ }^{\circ} \mathrm{C}$. After centrifugation at $12,000 \mathrm{rpm}$ for 15 min at $4{ }^{\circ} \mathrm{C}$, the supernatants were mixed with $2 \mathrm{~mL}$ of $45 \mathrm{mM}$ Na-acetate buffer (pH 5.0) containing $1 \mathrm{mM}$ $\rho$-nitrophenyl phosphate (Sigma, Saint Louis, MO, USA). After incubation at $37^{\circ} \mathrm{C}$ for $15 \mathrm{~min}$, the reaction was terminated by the addition of $1 \mathrm{~mL}$ of $1 \mathrm{M} \mathrm{NaOH}$. APase activity was spectrophotometrically detected at $405 \mathrm{~nm}$ and expressed as micromoles of $\rho$-nitrophenyl phosphate hydrolyzed per mg protein per min. Protein concentration in the extracts was analyzed using the Coomassie Brilliant Blue staining method [73].

\section{RNA extraction and sequencing}

Total RNA from roots of RY2 at 0 (LP) and 250 (HP) $\mu \mathrm{M} \mathrm{KH_{2 }} \mathrm{PO}_{4}$ treatments was isolated using Trizol reagent (Invitrogen, Carlsbad, CA, USA) following the manufacturer's instructions. RNA purity and integrity were assessed by Nanodrop 2000c Spectrophotometer (Thermo Fisher Scientific, Waltham, MA, USA) and Agilent 2100 (Agilent Technologies, Palo Alto, CA, USA), respectively. RNA sequencing analysis was conducted by Novogene Bioinformatics Technology Co., Ltd. (Beijing, China). RNA-seq libraries were constructed using the NEBNext ${ }^{\circledR}$ Ultra $^{\text {TM }}$ RNA Library Prep kit (NEB, Beverly, MA, USA), and the cDNA libraries were sequenced using an Illumina Hiseq ${ }^{\mathrm{TM}}$ platform (Illumina, San Diego, 
CA, USA). The 150-bp paired-end reads (PE150) were generated.

\section{Transcriptomic analysis}

RNA-seq raw data were obtained using the Casava v.1.8 program. The raw reads in FASTQ format were processed, and then the high-quality clean reads were obtained after removing adaptor, ploy- $\mathrm{N}$ and low-quality sequences. The final clean reads were assembled using Trinity software (version 2). For annotation, all assembled unigenes were searched against a number of public databases, including the National Center for Biotechnology Information (NCBI) non-redundant protein sequences $(\mathrm{Nr})$, the non-redundant nucleotide sequences $(\mathrm{Nt})$, the Protein Family (Pfam), the Clusters of Orthologous Groups of protein database (COG), the Swiss-Prot protein database, the GO and the KEGG databases.

The expression level of each gene was analyzed and represented by the expected number of fragments per kilobase of transcript sequence per millions base pairs (FPKM) using RSEM software with default settings [74]. Differentially expressed genes between two $P$ treatments were identified using DESeq2 [75]. Genes with $q$-value $<0.05$ and $\mid \log _{2}$ (fold change) $\mid \geq 1$ were assigned as differentially expressed. GO and KEGG enrichment analyses of DEGs were performed as previously described $[71,76]$. The interaction networks were analyzed by Cytoscape (version 3.8.0). The raw data were deposited in the Gene Expression Omnibus under GEO series number GSE171448.

\section{Validation of DEGs by qRT-PCR analysis}

A total of 13 DEGs were selected to assess the accuracy of RNA-seq data using qRT-PCR method. qRT-PCR analysis was performed according to SYBR Green Master Mix kit (Vazyme, China), and was monitored on a QuantStudio $^{\mathrm{TM}} 6$ Flex Real-Time System (Thermo Fisher Scientific, Waltham, MA, USA). Specific primers of the tested genes are listed in Additional file 12. The relative expression of candidate gene was calculated relative to the expression of reference gene $S g E F-1 a$ as previously described [37]. Three biological replicates were included in the qRT-PCR analysis.

\section{Statistical analysis}

Data analysis was performed for the mean and standard error calculation using Microsoft Excel 2003 (Microsoft Company, USA). One-way ANOVA and Student's $t$-test analyses were performed with the SPSS program (SPSS Institute, USA, v. 13.0).

\section{Abbreviations}

ACP: Acid phosphatase; ALMT: Aluminum-activated malate transporter; ATP: Adenosine triphosphate; BP: Biological processes; CC: Cellular components; COG: Clusters of orthologous groups of protein database; DEGs: Differentially expressed genes; dNTP: Deoxynucleoside triphosphate; FPKM: Expected number of fragments per kilobase of transcript sequence per millions base pairs; GO: Gene ontology; KEGG: Kyoto encyclopedia of genes and genomes; MATE: Multidrug and toxin extrusion; MF: Molecular function; NCBI: National center for biotechnology information; Nr: Non-redundant protein sequences; Nt: Non-redundant nucleotide sequences; PAP: Purple acid phosphatase; Pfam: Protein family; PHR1: PHOSPHATE STARVATION RESPONSE 1; PPCK: Phosphoenolpyruvate carboxylase kinase; PSI: Pi starvation induced; PSR: Pi starvation responses; PT: Pi transporter; qRT-PCR: Quantitative real-time polymerase chain reaction; RNA-seq: RNA sequencing; RNS: Ribonuclease; SPX: SYG1/ PHO81/XPR1; TFs: Transcription factors.

\section{Supplementary Information}

The online version contains supplementary material available at https://doi. org/10.1186/s12870-021-03249-2.

Additional file 1: Table S1. The decrease rate of growth parameters of stylo under 0 (LP) and $100 \mu \mathrm{M} \mathrm{KH}_{2} \mathrm{PO}_{4}$ relative to that in 250 (HP) $\mu \mathrm{M}$ $\mathrm{KH}_{2} \mathrm{PO}_{4}$ treatment.

Additional file 2: Table S2. Summary of stylo roots transcriptomes in 0 $(\mathrm{LP})$ and $250(\mathrm{HP}) \mu \mathrm{M} \mathrm{KH_{2 }} \mathrm{PO}_{4}$ supply treatments.

Additional file 3: Table S3. DEGs identified in stylo roots under 0 (LP) and 250 (HP) $\mu$ M KH2PO4 supply treatments.

Additional file 4: Figure S1. Clustering analysis of the DEGs under two $P$ conditions. The transcripts of DEGs were normalized as $\log _{2}$ (FPKM). Expression levels ranged from red to blue indicate high to low expression

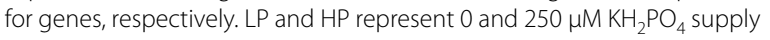
treatments, respectively.

Additional file 5: Table S4. DEGs related to transporters.

Additional file 6: Table S5. DEGs encoding putative phosphatases.

Additional file 7: Table S6. DEGs related to root growth.

Additional file 8: Table S7. Potential transcription factors involved in Pi signaling.

Additional file 9: Table S8. DEGs related to plant hormone signal transduction.

Additional file 10: Figure S2. Heatmap analysis of the DEGs belonging to SPX containing proteins. The transcripts of DEGs were normalized as $\log 2($ FPKM+1). Gene IDs were showed by the legend on the right. Expression levels ranged from red to blue indicate high to low expression

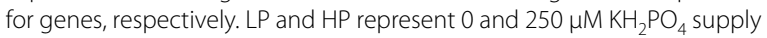
treatments, respectively.

Additional file 11: Figure S3. Correlation analysis of gene expression between transcriptome data and GRT-PCR results. Nine up-regulated and four down-regulated DEGs were selected for QRT-PCR analysis. Transcriptome data were plotted against data from qRT-PCR. Data are presented on a $\log _{2}$ scale.

Additional file 12: Table S9. Primers used for QRT-PCR analysis of the selected genes.

\section{Acknowledgements}

We thank Xiaoyan Zou for assistance in preparation of figures and Chun Liu for providing critical comments about this work.

\section{Authors' contributions}

X.M. and G.L. designed the research. Z.C., J.S. and X.L. performed the physiological experiments. Z.C. J.A. and J.A.C. carried out the transcriptomic analysis. Z.C., X.M., G.L., I.R., R.S.K., M.P. and X.M. analyzed the data and wrote the article. All authors read and approved the final manuscript. 


\section{Funding}

The research was supported by the National Natural Science Foundation of China (31801951, 31861143013, 31802125), the Modern Agro-industry Technology Research System (CARS-34), and the Integrated Demonstration of Key Techniques for the Industrial Development of Featured Crops in Rocky Desertification Areas of Yunnan-Guangxi-Guizhou Provinces (SMH2019-2021). The authors declare that none of the funding bodies have any role in the design of the study or collection, analysis, and interpretation of data as well as in writing the manuscript.

\section{Availability of data and materials}

The datasets are included in this article and its Additional files are available from the corresponding author on reasonable request. The datasets for this study can be found in the NCBI Gene Expression Omnibus under GEO series number of GSE171448.

\section{Declarations}

\section{Ethics approval and consent to participate}

The stylo seeds used in this study were provided by the Tropical Pasture Research Center, Institute of Tropical Crop Genetic Resources (TCGRI), Chinese Academy of Tropical Agriculture Sciences (CATAS), Hainan, China. All experimental researches were performed in accordance with the institutional and national guidelines of China.

\section{Consent for publication}

Not applicable.

\section{Competing interests}

The authors declare that they have no competing interests.

\section{Author details}

${ }^{1}$ Institute of Tropical Crop Genetic Resources, Chinese Academy of Tropical Agricultural Sciences, Haikou 571101, P.R. China. ${ }^{2}$ Hainan Key Laboratory for Sustainable Utilization of Tropical Bioresources, College of Tropical Crops, Hainan University, Haikou 570110, P.R. China. ${ }^{3}$ Alliance of Bioversity International and International Center for Tropical Agriculture, Cali A.A.6713, Colombia. ${ }^{4}$ Root Biology Center, State Key Laboratory for Conservation and Utilization of Subtropical Agro-bioresources, College of Natural Resources and Environment, South China Agricultural University, Guangzhou 510642, P.R. China.

Received: 12 May 2021 Accepted: 6 October 2021

Published online: 13 October 2021

\section{References}

1. Raghothama KG. Phosphate acquisition. Annu Rev Plant Physiol Plant Mol Biol. 1999;50:665-93.

2. Mora-Macías J, Ojeda-Rivera JO, Gutiérrez-Alanís D, Yong-Villalobos L, Oropeza-Aburto A, Raya-González J, et al. Malate-dependent Fe accumulation is a critical checkpoint in the root developmental response to low phosphate. Proc Natl Acad Sci U S A. 2017;114(17):3563-72.

3. Ao JH, Chen ZJ, Wu M, Lu X, Huang Z, Liao H. Phosphorus fractions of red soils in Guangdong province of South China and their bioavailability for five crop species. Soil Sci. 2014;179:514-21.

4. Kochian LV, Piñeros MA, Liu J, Magalhaes JV. Plant adaptation to acid soils: The molecular basis for crop aluminum resistance. Annu Rev Plant Biol. 2015;66:571-98.

5. Conley DJ, Paerl HW, Howarth RW, Boesch DF, Seitzinger SP, Havens KE, et al. Controlling eutrophication: nitrogen and phosphorus. Science. 2009;323(5917):1014-5.

6. Cordell D, Drangert J, White S. The story of phosphorus: global food security and food for thought. Glob Environ Chang. 2009;19:292-305.

7. Wu P, Shou H, Xu G, Lian X. Improvement of phosphorus efficiency in rice on the basis of understanding phosphate signaling and homeostasis. Curr Opin Plant Biol. 2013;16(2):205-12.

8. Ham BK, Chen J, Yan Y, Lucas WJ. Insights into plant phosphate sensing and signaling. Curr Opin Biotechnol. 2018:49:1-9.
9. Lynch JP. Root phenes for enhanced soil exploration and phosphorus acquisition: tools for future crops. Plant Physiol. 2011;156(3):1041-9.

10. Rao IM, Miles JW, Beebe SE, Horst WJ. Root adaptations to soils with low fertility and aluminium toxicity. Ann Bot. 2016;118(4):593-605.

11. Bayuelo-Jiménez JS, Gallardo-Valdéz M, Pérez-Decelis VA, MagdalenoArmas L, Ochoa I, Lynch JP. Genotypic variation for root traits of maize (Zea mays L.) from the Purhepecha Plateau under contrasting phosphorus availability. Field Crop Res. 2011;121(3):350-62.

12. Liu HT, White PJ, Li CJ. Biomass partitioning and rhizosphere responses of maize and faba bean to phosphorus deficiency. Crop Pasture Sci. 2016;67:847-56.

13. Lyu Y, Tang H, Li H, Zhang F, Rengel Z, Whalley WR, et al. Major crop species show differential balance between root morphological and physiological responses to variable phosphorus supply. Front Plant Sci. 2016;7:1939.

14. Mehra P, Pandey BK, Giri J. Improvement in phosphate acquisition and utilization by a secretory purple acid phosphatase (OsPAP21b) in rice. Plant Biotechnol J. 2017;15(8):1054-67.

15. Bhadouria J, Singh AP, Mehra P, Verma L, Srivastawa R, Parida SK, et al. Identification of purple acid phosphatases in chickpea and potential roles of CAPAP7 in seed phytate accumulation. Sci Rep. 2017;7(1):11012.

16. Zhu S, Chen M, Liang $C$, Xue $Y$, Lin S, Tian J. Characterization of purple acid phosphatase family and functional analysis of GMPAP7a/7b involved in extracellular ATP utilization in soybean. Front Plant Sci. 2020;11:661.

17. Liang C, Wang J, Zhao J, Tian J, Liao H. Control of phosphate homeostasis through gene regulation in crops. Curr Opin Plant Biol. 2014;21:59-66.

18. Chiou TJ, Lin SI. Signaling network in sensing phosphate availability in plants. Annu Rev Plant Biol. 2011;62:185-206.

19. Mitsukawa N, Okumura S, Shirano Y, Sato S, Kato T, Harashima S, et al. Overexpression of an Arabidopsis thaliana high-affinity phosphate transporter gene in tobacco cultured cells enhances cell growth under phosphate-limited conditions. Proc Natl Acad Sci U S A. 1997;94(13):7098-102.

20. Mudge SR, Rae AL, Diatloff E, Smith FW. Expression analysis suggests novel roles for members of the Pht1 family of phosphate transporters in Arabidopsis. Plant J. 2002;31(3):341-53.

21. Sun S, Gu M, Cao Y, Huang X, Zhang X, Ai P, et al. A constitutive expressed phosphate transporter, OsPht 1;1, modulates phosphate uptake and translocation in phosphate-replete rice. Plant Physiol. 2012;159(4):1571-81.

22. Wang $X$, Wang $Y$, Piñeros MA, Wang Z, Wang W, Li C, et al. Phosphate transporters OsPHT1;9 and OsPHT1;10 are involved in phosphate uptake in rice. Plant Cell Environ. 2014;37(5):1159-70.

23. Qin L, Zhao J, Tian J, Chen L, Sun Z, Guo Y, et al. The high-affinity phosphate transporter GmPT5 regulates phosphate transport to nodules and nodulation in soybean. Plant Physiol. 2012;159(4):1634-43.

24. Chen L, Qin L, Zhou L, Li X, Chen Z, Sun L, et al. A nodule-localized phosphate transporter GmPT7 plays an important role in enhancing symbiotic N2 fixation and yield in soybean. New Phytol. 2019;221(4):2013-25.

25. Wang L, Lu S, Zhang Y, Li Z, Du X, Liu D. Comparative genetic analysis of Arabidopsis purple acid phosphatases AtPAP10, AtPAP12, and AtPAP26 provides new insights into their roles in plant adaptation to phosphate deprivation. J Integr Plant Biol. 2014;56(3):299-314.

26. Li RJ, Lu WJ, Guo CJ, Li XJ, Gu JT, Xiao K. Molecular characterization and functional analysis of OSPHY1, a purple acid phosphatase (PAP)-type phytase gene in rice (Oryza sativa L.). J Integr Plant Biol. 2012;11:1217-26.

27. Liang C, Sun L, Yao Z, Liao H, Tian J. Comparative analysis of PVPAP gene family and their functions in response to phosphorus deficiency in common bean. PLoS One. 2012;7(5):e38106.

28. Kong Y, Li X, Wang B, Li W, Du H, Zhang C. The soybean purple acid phosphatase GmPAP14 predominantly enhances external phytate utilization in plants. Front Plant Sci. 2018;9:292.

29. Li C, Zhou J, Wang X, Liao H. A purple acid phosphatase, GmPAP33, participates in arbuscule degeneration during arbuscular mycorrhizal symbiosis in soybean. Plant Cell Environ. 2019;42(6):2015-27.

30. Guo W, Zhao J, Li X, Qin L, Yan X, Liao H. A soybean $\beta$-expansin gene GmEXPB2 intrinsically involved in root system architecture responses to abiotic stresses. Plant J. 2011;66(3):541-52.

31. Yu Z, Kang B, He X, Lv S, Bai Y, Ding W, et al. Root hair-specific expansins modulate root hair elongation in rice. Plant J. 2011;66(5):725-34. 
32. Chandra A. Diversity among Stylosanthes species: habitat, edaphic and agro-climatic affinities leading to cultivar development. J Environ Biol. 2009;30(4):471-8.

33. Liu GD, Bai CJ, Wang DJ, He HX. Stylosanthes cultivars in China: their development and performance. In: Chakraborty S, editor. High-yielding anthracnose-resistant Stylosanthes for agricultural systems: Australian Centre for International Agricultural Research (ACIAR) Press; 2004. p. 156-8.

34. Guo PF, Liu PD, Lei J, Chen CH, Qiu H, Liu GD, et al. Improvement of plant regeneration and Agrobacterium-mediated genetic transformation of Stylosanthes guianensis. Trop Grassl Forrajes. 2019;7:480-92.

35. Sun L, Liang C, Chen Z, Liu P, Tian J, Liu G, et al. Superior aluminium (Al) tolerance of Stylosanthes is achieved mainly by malate synthesis through an Al-enhanced malic enzyme, SgME1. New Phytol. 2014;202(1):209-19.

36. Chen Z, Sun L, Liu P, Liu G, Tian J, Liao H. Malate synthesis and secretion mediated by a manganese-enhanced malate dehydrogenase confers superior manganese tolerance in Stylosanthes guianensis. Plant Physiol. 2015;167(1):176-88

37. Liu P, Cai Z, Chen Z, Mo X, Ding X, Liang C, et al. A root-associated purple acid phosphatase, SgPAP23, mediates extracellular phytate-P utilization in Stylosanthes guianensis. Plant Cell Environ. 2018;41(12):2821-34.

38. Liu PD, Xue YB, Chen ZJ, Liu GD, Tian J. Characterization of purple acid phosphatases involved in extracellular dNTP utilization in Stylosanthes. J Exp Bot. 2016;67(14):4141-54.

39. Du YM, Tian J, Liao H, Bai CJ, Yan XL, Liu GD. Aluminium tolerance and high phosphorus efficiency helps Stylosanthes better adapt to low-P acid soils. Ann Bot. 2009;103(8):1239-47.

40. Gamuyao R, Chin JH, Pariasca-Tanaka J, Pesaresi P, Catausan S, Dalid C, et al. The protein kinase Pstol 1 from traditional rice confers tolerance of phosphorus deficiency. Nature. 2012;488(7412):535-9.

41. Wu W, Lin Y, Liu P, Chen Q, Tian J, Liang C. Association of extracellular dNTP utilization with a GmPAP1-like protein identified in cell wall proteomic analysis of soybean roots. J Exp Bot. 2018;69(3):603-17.

42. Lin Y, Chen G, Hu H, Yang X, Zhang Z, Jiang X, et al. Phenotypic and genetic variation in phosphorus-deficiency-tolerance traits in Chinese wheat landraces. BMC Plant Biol. 2020;20(1):330.

43. Lan P, Li WF, Schmidt W. Complementary proteome and transcriptome profiling in phosphate-deficient Arabidopsis roots reveals multiple levels of gene regulation. Mol Cell Proteomics. 2012;11(11):1156-66.

44. Secco D, Jabnoune M, Walker H, Shou H, Wu P, Poirier Y, et al. Spatio-temporal transcript profiling of rice roots and shoots in response to phosphate starvation and recovery. Plant Cell. 2013;25(11):4285-304.

45. Zeng HQ, Wang GP, Zhang YQ, Hu XY, Pi EX, Zhu YY, et al. Genome-wide identification of phosphate-deficiency-responsive genes in soybean roots by high-throughput sequencin. Plant Soil. 2016;398:207-27.

46. Feng H, Li B, Zhi Y, Chen J, Li R, Xia X, et al. Overexpression of the nitrate transporter, OsNRT2.3b, improves rice phosphorus uptake and translocation. Plant Cell Rep. 2017;36(8):1287-96.

47. Liu F, Chang XJ, Ye Y, Xie WB, Wu P, Lian XM. Comprehensive sequence and whole-life-cycle expression profile analysis of the phosphate transporter gene family in rice. Mol Plant. 2011;4(6):1105-22.

48. Cao Y, Liu J, Li Y, Zhang J, Li S, An Y, et al. Functional analysis of the phosphate transporter gene MtPT6 from Medicago truncatula. Front Plant Sci. 2021;11:620377.

49. Karthikeyan AS, Varadarajan DK, Mukatira UT, D'Urzo MP, Damsz B, Raghothama KG. Regulated expression of Arabidopsis phosphate transporters. Plant Physiol. 2002;130(1):221-33.

50. Shin H, Shin HS, Dewbre GR, Harrison MJ. Phosphate transport in Arabidopsis: Pht 1;1 and Pht 1;4 play a major role in phosphate acquisition from both low- and high-phosphate environments. Plant J. 2004;39(4):629-42.

51. Ai P, Sun S, Zhao J, Fan X, Xin W, Guo Q, et al. Two rice phosphate transporters, OsPht1;2 and OsPht1;6, have different functions and kinetic properties in uptake and translocation. Plant J. 2009;57(5):798-809.

52. Peng W, Wu W, Peng J, Li J, Lin Y, Wang Y, et al. Characterization of the soybean GmALMT family genes and the function of GmALMT5 in response to phosphate starvation. J Integr Plant Biol. 2018;60(3):216-31.

53. Magalhaes JV, Liu J, Guimarães CT, Lana UG, Alves VM, Wang YH, et al. A gene in the multidrug and toxic compound extrusion (MATE) family confers aluminum tolerance in sorghum. Nat Genet. 2007;39(9):1156-61.

54. Liang C, Piñeros MA, Tian J, Yao Z, Sun L, Liu J, et al. Low pH, aluminum, and phosphorus coordinately regulate malate exudation through
GmALMT1 to improve soybean adaptation to acid soils. Plant Physiol. 2013;161(3):1347-61.

55. Chen Q, Wang L, Liu D, Ma S, Dai Y, Zhang X, et al. Identification and expression of the multidrug and toxic compound extrusion (MATE) gene family in Capsicum annuum and Solanum tuberosum. Plants. 2020;9(11):1448.

56. Li XF, Zuo FH, Ling GZ, Li YY, Yu YX, Yang PQ, et al. Secretion of citrate from roots in response to aluminum and low phosphorus stresses in Stylosanthes. Plant Soil. 2009;325:219-29.

57. Haran S, Logendra S, Seskar M, Bratanova M, Raskin I. Characterization of Arabidopsis acid phosphatase promoter and regulation of acid phosphatase expression. Plant Physiol. 2000;124(2):615-26.

58. Zhang Q, Wang C, Tian J, Li K, Shou H. Identification of rice purple acid phosphatases related to phosphate starvation signalling. Plant Biol. 2011;13(1):7-15

59. Li C, Gui S, Yang T, WalkT, Wang X, Liao H. Identification of soybean purple acid phosphatase genes and their expression responses to phosphorus availability and symbiosis. Ann Bot. 2012;109(1):275-85.

60. Luo J, Liu Y, Zhang H, Wang J, Chen Z, Luo L, et al. Metabolic alterations provide insights into Stylosanthes roots responding to phosphorus deficiency. BMC Plant Biol. 2020;20(1):85.

61. Valdés-López O, Arenas-Huertero C, Ramírez M, Girard L, Sánchez F, Vance CP, et al. Essential role of MYB transcription factor: PVPHR1 and microRNA: PvmiR399 in phosphorus-deficiency signalling in common bean roots. Plant Cell Environ. 2008;31(12):1834-43.

62. Guo M, Ruan W, Li C, Huang F, Zeng M, Liu Y, et al. Integrative comparison of the role of the PHOSPHATE RESPONSE1 subfamily in phosphate signaling and homeostasis in rice. Plant Physiol. 2015;168(4):1762-76.

63. Sun L, Song L, Zhang Y, Zheng Z, Liu D. Arabidopsis PHL2 and PHR1 act redundantly as the key components of the central regulatory system controlling transcriptional responses to phosphate starvation. Plant Physiol. 2016;170(1):499-514.

64. Xue YB, Xiao BX, Zhu SN, Mo XH, Liang CY, Tian J, et al. GmPHR25, a GmPHR member up-regulated by phosphate starvation, controls phosphate homeostasis in soybean. J Exp Bot. 2017;68(17):4951-67.

65. Chen YF, Li LQ, Xu Q, Kong YH, Wang H, Wu WH. The WRKY6 transcription factor modulates PHOSPHATE1 expression in response to low Pi stress in Arabidopsis. Plant Cell. 2009;21(11):3554-66.

66. Devaiah BN, Karthikeyan AS, Raghothama KG. WRKY75 transcription factor is a modulator of phosphate acquisition and root development in Arabidopsis. Plant Physiol. 2007;143(4):1789-801.

67. Yao Z, Tian J, Liao H. Comparative characterization of GmSPX members reveals that GmSPX3 is involved in phosphate homeostasis in soybean. Ann Bot. 2014;114(3):477-88.

68. Duan K, Yi K, Dang L, Huang H, Wu W, Wu P. Characterization of a sub-family of Arabidopsis genes with the SPX domain reveals their diverse functions in plant tolerance to phosphorus starvation. Plant J. 2008:54(6):965-75.

69. Puga MI, Mateos I, Charukesi R, Wang Z, Franco-Zorrilla JM, de Lorenzo L, et al. SPX1 is a phosphate-dependent inhibitor of PHOSPHATEF STARVATION RESPONSE 1 in Arabidopsis. Proc Natl Acad Sci U S A. 2014;111(41):14947-52.

70. LV Q, Zhong Y, Wang Y, Wang Z, Zhang L, Shi J, et al. SPX4 negatively regulates phosphate signaling and homeostasis through its interaction with PHR2 in rice. Plant Cell. 2014;26(4):1586-97.

71. Jia Y, Li X, Liu Q, Hu X, Li J, Dong R, et al. Physiological and transcriptomic analyses reveal the roles of secondary metabolism in the adaptive responses of Stylosanthes to manganese toxicity. BMC Genomics. 2020;21(1):861.

72. Murphy J, Riley JP. A modified single solution method for the determination of phosphate in natural waters. Anal Chim Acta. 1962;27:31-6.

73. Bradford MM. A rapid and sensitive method for the quantitation of microgram quantities of protein utilizing the principle of protein-dye binding. Anal Biochem. 1976;72:248-54.

74. Li B, Dewey CN. RSEM: accurate transcript quantification from RNA-Seq data with or without a reference genome. BMC Bioinformatics. 2011;12:323.

75. Love MI, Huber W, Anders S. Moderated estimation of fold change and dispersion for RNA-seq data with DESeq2. Genome Biol. 2014;15(12):550.

76. Kanehisa M, Goto S. KEGG: Kyoto encyclopedia of genes and genomes. Nucleic Acids Res. 2000;28:27-30.

\section{Publisher's Note}

Springer Nature remains neutral with regard to jurisdictional claims in published maps and institutional affiliations. 